\title{
Proteolysis-inducing factor core peptide mediates dermcidin-induced proliferation of hepatic cells through multiple signalling networks
}

\author{
ALASTAIR G. LOWRIE ${ }^{1}$, PAUL DICKINSON ${ }^{2,3}$, NICHOLAS WHEELHOUSE ${ }^{1}$, \\ GRANT D. STEWART ${ }^{1}$, ALAN J. ROSS ${ }^{2}$, THORSTEN FORSTER ${ }^{2}$ and JAMES A. ROSS ${ }^{1}$ \\ ${ }^{1}$ Tissue Injury and Repair Group, MRC Centre for Regenerative Medicine, ${ }^{2}$ Division of Pathway Medicine, \\ Chancellor's Building, The University of Edinburgh Medical School, Royal Infirmary of Edinburgh, \\ 49 Little France Crescent, Edinburgh, EH16 4SB; ${ }^{3}$ Centre for Systems Biology at Edinburgh, \\ The University of Edinburgh, Darwin Building, Room 3.17B, King's Buildings \\ Campus, Mayfield Road, Edinburgh, EH9 3JU, UK
}

Received April 7, 2011; Accepted May 13, 2011

DOI: $10.3892 /$ ijo.2011.1064

\begin{abstract}
Dermcidin is a candidate oncogene capable of increasing the number of cultured neuronal, breast cancer and prostate cancer cells and improving the survival of hepatic cells. The dermcidin gene encodes the proteolysis-inducing factor core peptide (PIF-CP) and the skin antimicrobial peptide DCD-1. The peptide responsible for inducing proliferation of cells and the mechanisms involved are unknown. In this study, we confirmed a proliferative effect of dermcidin overexpression of $20 \%(\mathrm{p}<0.02)$ in the $\mathrm{HuH} 7$ human hepatic cell line. Proliferation was abrogated by prevention of PIF-CP translation or inactivation of its calcineurin-like phosphatase domain by site-directed mutagenesis. Prevention of DCD-1 translation had no effect. Treatment of cells with a 30 amino acid synthetic PIF-CP induced an analogous increase in proliferation of $14 \%$. Microarray analysis of PIF-CP-treated cells revealed low but significant changes in 111 potential mediator genes. Pathway analysis revealed several gene networks involved in the cellular response to the peptide, one with VEGFB as a hub and two other networks converging on FOS and MYC. Quantitative PCR confirmed direct upregulation of VEGFB. These data reveal PIF-CP as the key mediator of dermcidin-induced proliferation and demonstrate induction of key oncogenic pathways.
\end{abstract}

\section{Introduction}

The first evidence of dermcidin (DCD)-induced cell proliferation arose from studies of the effect of over-expression of the

Correspondence to: Dr James A. Ross, Tissue Injury and Repair Group, MRC Centre for Regenerative Medicine, Chancellor's Building, The University of Edinburgh Medical School, Royal Infirmary of Edinburgh, 49 Little France Crescent, Edinburgh, EH16 4SB, UK

E-mail: j.a.ross@ed.ac.uk

Key words: proliferation, oncogene, mutagenesis, dermcidin, microarray identical gene, DSEP, in neural cells (1). DSEP was found to decrease the ability of all-trans-retinoic acid to slow cell proliferation and at 3 days post-treatment almost three times more DSEP-overexpressing cells than sham-transfected cells were present. More recently, Porter et al demonstrated increased numbers of $21 \mathrm{NT}$ breast cancer cells after stable transfection with DCD following 5 and 7 days of cell culture compared to cells transfected with empty vector (2). Work from our group showed similar results using DCD-transfected prostate cancer cells (PC-3M) (3). Additionally, significantly more DCD-transfected PC-3M cells stained with Ki-67 compared with those transfected with the empty vector. Differential DCD expression has also recently been demonstrated in human pancreatic, bile duct and gastro-esophageal carcinoma but not in benign tissue (4). These studies suggest that DCD-induced proliferation could have important effects on human carcinogenesis and tumour progression.

The DCD gene produces a 110-amino acid polypeptide consisting of a 19 amino acid signal peptide, the 30 amino acid proteolysis inducing factor-core peptide (PIF-CP), a 13 amino acid propetide and the 47 amino acid DCD-1 peptide. The peptide responsible for the proliferative effects of DCD has yet to be confirmed. At least 2 of the peptides are biologically active; firstly the core peptide of proteolysis-inducing factor (PIF-CP) $(3,4)$, which is identical to the neuronal survival factor Y-P30 (5) and when glycosylated forms the cachectic factor described by Todorov et al (6); and secondly DCD-1, which has antibiotic activity (7). Structural analysis of PIF-CP has demonstrated cleavage of a signal peptide and targeting to the secretory pathway (8). This predicts an extracellular action consistent with the putative role of DCD as a growth factor and oncogene (2). In addition, the central sequence of the PIF-CP has homology with the phosphatase domain of calcineurin, and appears to be involved in the pro-survival effects of dermcidin expression $(5,8)$. However, although calcineurin has been suggested to be involved in T-cell activation (9), it may inhibit proliferation in neoplastic cells via cdk-4 dephosphorylation (10) and has been targeted in anti-proliferative 
strategies (11). PIF-CP/Y-P30 also binds to calreticulin, which induces keratinocyte proliferation $(12,13)$. The target receptor for DCD-1 is not known but low-affinity and high-affinity DCD receptors on breast cancer cells and a recently described PIF receptor on skeletal muscle have been identified $(9,14)$. Whether these receptors mediate proliferation and what their peptide ligands are remains unknown.

Dermcidin induces multiple changes in gene expression which have the potential to induce cell proliferation. Glycosylated PIF has been demonstrated to induce activation of NF- $\kappa \beta$ and STAT3 transcription pathways in hepatic cells (15), in some endothelial subtypes (16) and in monocytes and Kupffer cells (17). Both NF- $\kappa \beta$ and STAT3 are known to induce proliferation in a variety of cell types including pancreatic carcinoma and hepatic cells (18-23). Glycosylated PIF has also been shown to increase IL-6 and IL-8 expression in hepatic and endothelial cells, in which these cytokines induce proliferation $(15,16,24,25)$. DCD overexpression results in an attenuated response of neuronal cells to treatment with all-trans retinoic acid, a differentiating agent with antiproliferative transcriptional effects which also interacts with calreticulin $(26,27)$.

The aim of this study was to investigate DCD-stimulated proliferation in the hepatic carcinoma cell line $\mathrm{HuH7}$. $\mathrm{HuH} 7$ cells do not express DCD endogenously but respond to overexpression with an improved survival under conditions of oxidative stress (8). We further sought to determine the peptide subunit of the DCD polypeptide responsible for proliferation and to investigate the alterations in gene expression associated with the proliferative response.

\section{Materials and methods}

Polymerase chain reaction (PCR), cloning, site-directed mutagenesis and transfection were performed as previously described (8) and are detailed in brief below.

PCR. PCR of vector DNA and cellular cDNA was performed using primers to the full length native dermcidin cDNA (TAGN, Newcastle, UK). Forward primer: CTCGGATCCGC CGCCATGAGGTTCATGACTCTCC; reverse primer, CAGA ATTCCTGGGTATCATTTCTCAGCT. Twenty-five $\mu \mathrm{l}$ reaction mixtures containing $0.75 \mu 125 \mathrm{mM} \mathrm{MgCl} 2,2.5 \mu \mathrm{l}$ taq poly $10 \mathrm{X}$ buffer, $2.5 \mu \mathrm{l}$ dNTPs, $1 \mathrm{mM}$ forward and reverse primers and $1 \mu \mathrm{l}$ taq polymerase at a 1 in 5 dilution were made up in nuclease-free water (all from Promega, Poole, UK). A standard cycle of $95^{\circ} \mathrm{C}$ for $5 \mathrm{~min}$ followed by 35 cycles of $95^{\circ} \mathrm{C}$ for $1 \mathrm{~min}, 56^{\circ} \mathrm{C}$ for $1 \mathrm{~min}$ and $72^{\circ} \mathrm{C}$ for $1 \mathrm{~min}$ then $10 \mathrm{~min}$ at $72^{\circ} \mathrm{C}$ was used. Samples were run on $1.4 \%$ agarose gels, stained with ethidium bromide and visualised under UV illumination.

Site-directed mutagenesis. Site-directed mutagenesis of the pcDNA3.1+dermcidin vector was performed using a Quikchange II kit (Stratagene, Amsterdam, The Netherlands) according to the manufacturer's instructions. Primers used were: N32Q forward-CCAGGATCGGGGCAGCCTTGCCATGAAGC; reverse-GCTTCATGGCAAGGCTGCCCCGATCCTGG. N44Q forward-CAGCAGCTCAAAAGGAACAGGCAGGT GAAGACCCAG; reverse-CTGGGTCTTCACCTGCCTGTT
CCTTTTGAGCTGCTG. ProP STOP forward-TGCAGGTG AAGACCCATAGTTAGCCAGACAGGCAC; reverse-GTGC CTGTCTGGCTAACTATGGGTCTTCACCTGCA. Y-P30 STOP forward-CTGGTCTGTGCCTAGGATCCAGAGGCC; reverse-GGCCTCTGGATCCTAGGCACAGACCAG. H35N forward-CGGGGAACCCTTGCAATGAAGCATCAGCAGC; reverse-GCTGCTGATGCTTCATTGCAAGGGTTCCCCG. Double N32Q, N44Q mutants were created by mutation of the pcDNA3.1+dermcidin N32Q plasmid with N44Q primers.

Cloning. Vectors were transformed into TOP10 Eschericia coli (Invitrogen, Paisley, UK) as per the manufacturer's instructions and plated on LB agar plus $50 \mu \mathrm{g} / \mathrm{ml}$ ampicillin (Sigma, Poole, UK). Colonies were screened for insert incorporation by PCR and incubated in $3 \mathrm{ml} \mathrm{LB}+50 \mu \mathrm{g} / \mathrm{ml}$ ampicillin minibroths overnight at $37^{\circ} \mathrm{C}$ with agitation. Plasmids were prepared by alkaline lysis and ethanol precipitation. All plasmids were sequenced prior to large scale culture and purification using an Endofree plasmid maxi kit (Qiagen, Crawley, UK).

Transfection and cell culture. Plasmids were transfected into the $\mathrm{HuH} 7$ cell line (European Collection of Cell Cultures, UK) using Fugene (Roche Applied Science, Lewes, UK) according to the manufacturer's instructions. Stable transfectants were selected by culture in $600 \mu \mathrm{g} / \mathrm{ml} \mathrm{G} 418$ (Sigma). Cells were maintained at $37^{\circ} \mathrm{C}$ in a $5 \% \mathrm{CO}_{2}$ in air atmosphere in Dulbecco's modified Eagle's medium with $10 \% \mathrm{FCS}, 50 \mathrm{U} / \mathrm{ml}$ penicillin, $50 \mu \mathrm{g} / \mathrm{ml}$ streptomycin and 2 mmol glutamine (Gibco-BRL, Paisley, UK). Transfection was confirmed by PCR and Western blotting for DCD and neomycin phosphotransferase.

Synthetic PIF peptide. A synthesised, $>95 \%$ purity, full length PIF-CP/Y-P30 peptide of 30 amino acids, YDPEAASAP GSGNPCHEASAAQKENAGEDP, was purchased from Albachem (Gladsmuir, UK). The peptide was added to cell cultures at a range of concentrations and cells were incubated under standard conditions for 24 hours prior to BrDU immunocytochemistry or RNA extraction.

RNA preparation and reverse transcription. For RNA extraction cells were seeded at $1 \times 10^{6}$ per well in 6-well plates and incubated overnight under standard conditions. RNA was extracted using Trizol (Life Technologies, Paisley, UK) according to the manufacturer's instructions. Samples were DNAse treated using RQ1 DNAse (Promega) according to the manufacturer's instructions. Reverse transcription was performed in $20 \mu \mathrm{l}$ reactions containing $10 \mu \mathrm{l}$ of RNA sample plus $10 \mu \mathrm{l}$ of RT mix $\left(4 \mu 125 \mathrm{mM} \mathrm{MgCl}_{2}, 2 \mu 1\right.$ reverse transcription 10X buffer, $2 \mu \mathrm{l}$ dNTP mixture, $1 \mu \mathrm{l}$ oligo(dT) 15 primer, $0.5 \mu 1 \mathrm{AMV}$ reverse transcriptase and $0.5 \mu 1$ recombinant RNasin ribonuclease inhibitor, Promega). Samples were then incubated in a thermal cycler (PHC-3, Techne, Stone, UK) for $1 \mathrm{~h}$ at $42^{\circ} \mathrm{C}$ followed by $5 \mathrm{~min}$ at $99^{\circ} \mathrm{C}$.

Protein preparation and quantification. Protein lysates were prepared using radio-immunoprecipitation assay (RIPA) buffer (1X PBS, 1\% Nonidet P-40 (BDH Chemicals, Poole, UK), $0.5 \%$ sodium deoxycholate and $0.1 \%$ SDS). One protease inhibitor tablet (Roche) was added to each $10 \mathrm{ml}$ of RIPA 
prior to use. Culture medium was removed and cells washed with sterile PBS. RIPA buffer $(500 \mu \mathrm{l})$ was then added to each well and cells lysed by scraping and passaging through a $21 \mathrm{G}$ needle. Lysates were placed in microcentrifuge tubes and centrifuged at $10,000 \mathrm{~g}$ for $10 \mathrm{~min}$ at $4^{\circ} \mathrm{C}$. The resultant protein supernatant was transferred to a fresh microcentrifuge tube for protein assay. Protein concentrations were determined using a Bio-Rad DC protein assay kit according to the manufacturer's instructions.

Western blotting. Western blot analyses were performed using $12.5 \%$ Bis-Tris gels (Bio-Rad, Hemel Hempstead, UK) and a Bio-Rad Miniprotean II system. Wells were loaded with $10 \mu \mathrm{g}$ of protein pre-incubated with LSB. Gels were run at $100 \mathrm{~V}$ for $\sim 1 \mathrm{~h}$ and transferred to nitrocellulose membranes (Bio-Rad) by semi-dry blotting at $100 \mathrm{~V}$ for $1 \mathrm{~h}$. Membranes were incubated for $1 \mathrm{~h}$ at room temperature with mouse anti-neomycin phosphotransferase primary antibody (Upstate, Watford, UK) at $1 \mu \mathrm{g} / \mathrm{ml}$ in $5 \%$ Marvel in tris-buffered saline. They were then washed for 5 min 3 times in $0.05 \%$ Tween (Sigma) in TBS and incubated for $1 \mathrm{~h}$ at room temperature with goat anti-mouse peroxidise-linked secondary antibody (Santa Cruz Biotechnology, Heidelberg, Germany) at 1 in 100 in 5\% Marvel in tris-buffered saline. Following a further 3 washes chemiluminescence was performed using the Amersham ECL system (Amersham Biosciences Ltd., Buckinghamshire, UK).

Bromodeoxyuridine labelling and immunocytochemistry. For immunocytochemical analysis $\mathrm{HuH7}$ cells were seeded at 10,000 cells per well in 8-well chambered slides (Nunc, VWR International, Poole, UK) and cultured overnight under standard conditions. In experiments in which the synthetic PIF peptide was used, this was added at the desired concentration and cells cultured for a further $24 \mathrm{~h}$. Cells were then labelled by incubation for $1 \mathrm{~h}$ with 1 in 1000 bromodeoxyuridine (BrDU, Cell Proliferation Labelling Reagent, Amersham, Chalfont St Giles, UK). Culture chambers were removed and slides washed in PBS prior to overnight fixation at $4^{\circ} \mathrm{C}$ in $80 \%$ ethanol. Slides were then washed in PBS for $10 \mathrm{~min}$ and incubated in $5 \mathrm{M} \mathrm{HCl}$ for $45 \mathrm{~min}$ at room temperature. Two further 5-min PBS washes were performed and the chambers on the slides were demarcated using a greasepen. Slides were blocked by incubation in $50 \mu \mathrm{l}$ per well of $20 \%$ normal goat serum (DakoCytomation, Ely, UK) in PBS plus $0.05 \%$ Tween-20 for $10 \mathrm{~min}$ at room temperature. Slides were then incubated for $1 \mathrm{~h}$ at room temperature with $50 \mu \mathrm{l}$ per well of monoclonal rat anti-BrDU antibody (Oxford Biotechnology, Kidlington, UK) at 1 in 100 in blocking solution and washed 3 times in PBS. Slides were incubated for $30 \mathrm{~min}$ at room temperature with $50 \mu \mathrm{l}$ per well of goat anti-rat peroxidaselinked secondary antibody (Santa Cruz Biotechnology) at 1 in 300 in blocking solution and washed again 3 times with PBS.

Slides were stained using a liquid DAB + substratechromogen system (Dako) according to the manufacturer's instructions and counterstained with haematoxylin. A light microscope and graticule were used to count at least 500 nuclei per chamber.

Microarray hybridisation and data analysis. For use in microarray experiments $1 \times 10^{6} \mathrm{HuH} 7$ cells per well were seeded in 6-well plates and incubated overnight prior to incubation with $10 \mathrm{ng} / \mathrm{ml}$ of synthetic PIF peptide for $24 \mathrm{~h}$. The experiment was performed in sextuplicate. Total RNA was extracted and subjected to a modification of the Agilent low RNA input Fluorescent linear amplification protocol (Agilent, South Queensferry, UK). The manufacturer's protocol was followed with the exception of using $1.2 \mu \mathrm{l}$ of Cy3- or Cy5-labeled CTP $(10 \mathrm{mM})$ during the cRNA synthesis step. Arrays used were Human cDNA Clone Set Array Version 2 arrays (MRC HGMP-RC, Cambridge, UK).

Microarray hybridisation and washing was performed according to the Agilent protocol following a reciprocal sample labelling and hybridisation dye-swap scheme. The 6 synthetic PIF peptide-treated samples were co-hybridised with the 6 control samples, with one dye-swap array for each of these, bringing the total number of arrays to 12 , hybridised with 24 samples. Slides were scanned using the Agilent 2505B microarray scanner and images analysed using Agilent feature extraction software. Data were analysed using R/Bioconductor and in particular the limma package (28) for steps consisting of background noise correction, normalisation and testing of statistical hypotheses. Briefly, measured background noise in the raw data was subtracted from the measured signal for each probe. For purposes of normalisation, an assumption of global similarity between samples and arrays was made as only a small proportion of probes were expected to change between the biological conditions under investigation. Withinarray distribution of $\log 2$ scale expression ratios between test and control sample was non-linearly centred around 0 by way of a locally weighted regression algorithm (LOWESS). The normalised expression ratios where then made comparable across arrays by matching the per-array distributions to one another, using median absolute deviation estimates for this scaling. A statistical null hypothesis of 'no difference in mean expression between PIF and control' was then tested for each gene, using a linear model with an empirical Bayes moderated t-statistic (moderated by variance information borrowed from multiple genes). Due to the presence of dye swap arrays, dye effect was also accounted for in this model. For the purposes of this analysis, genes with an estimate of statistical significance of $\mathrm{p} \leq 0.05$ and a differential expression cut-off of 1.25-fold up or down-regulation. A multiple testing correction of p-values was not applied, given that the purpose of the microarray analysis here is to provide a sorted list of statistically relevant genes for further follow-up. A proportion of false-positive results was considered acceptable due to use of other validation techniques. Microarray data have been deposited in the GPX MIAME compliant database at http://gpx.gti.ed.ac.uk/ (accession no. GPX-00080.1 will be made available upon publication).

Network analysis was performed after upload of a gene list of 111 differentially expressed genes as input for the Ingenuity Pathways Analysis software application (Ingenuity ${ }^{\circledR}$ Systems, Redwood City, CA). The IPA Knowledge Base, a comprehensive manually curated database of biological interactions for human, mouse and rat genes was used to construct pathways and networks. IPA maps each gene identifier in the uploaded dataset (focus genes) to its corresponding object in the IPA Knowledge Base and overlays these onto a global molecular network developed from the Knowledge Base. Networks of 
focus genes were then algorithmically generated based on connectivity and assigned a significance score representing the statistical likelihood of chance occurrence. A high number of focus genes within a network leads to a higher network score (negative exponent of respective p-value). For functional analysis, differentially regulated genes associated with biological functions and/or diseases in the Ingenuity Knowledge Base were analysed using a Fisher's exact test to calculate a p-value determining the probability that each biological function and/or disease assigned to that data set is due to chance alone. For canonical pathways analysis, genes associated with a canonical pathway in the Ingenuity Knowledge Base were analysed in 2 ways: i) a ratio of the number of genes from the data set that map to the pathway divided by the total number of genes that map to the canonical pathway was calculated; ii) Fisher's exact test was used to calculate a p-value determining the probability that the association between the genes in the dataset and the canonical pathway is explained by chance alone.

Real-time PCR. Real-time PCR for VEGF-B was performed using an ABI 7900HT Fast Real-Time PCR System (Applied Biosystems, Warrington, UK) according to the manufacturer's instructions. The 18S rRNA gene was used as an endogenous control to normalize for differences in the amount of total RNA in each sample. Eukaryotic 18S rRNA endogenous control (VIC/TAMRA probe, primer limited) and VEGF-B TaqMan Gene Expression Assays (assay id Hs00173634_m1) were purchased from Applied Biosystems.

Real-time PCR reactions $(10 \mu \mathrm{l})$ were set up consisting of $5 \mu \mathrm{l}$ TaqMan Universal PCR Master Mix (Applied Biosystems), $0.5 \mu \mathrm{l}$ TaqMan Gene Expression Assays and $4.5 \mu \mathrm{l}$ sample cDNA. Each PCR reaction contained $6.5 \mathrm{ng}$ of reverse transcribed RNA in $10 \mu \mathrm{l}$. All samples were run in triplicate in a 384-well real-time PCR plate (Applied Biosystems). Wells were heat-sealed with plastic film. The plate was centrifuged at $4000 \mathrm{~g}$ for $1 \mathrm{~min}$ then inserted into the ABI 7900HT. Conditions for the PCR reaction were 2 min at $50^{\circ} \mathrm{C}, 15 \mathrm{~min}$ at $95^{\circ} \mathrm{C}$ and then 40 cycles, each consisting of $15 \mathrm{secs}$ at $95^{\circ} \mathrm{C}$, and $1 \mathrm{~min}$ at $60^{\circ} \mathrm{C}$. Cycle-cycle changes in fluorescence in each sample were measured and a kinetic profile of amplification over the 40-cycle PCR reaction was generated. Only samples with an $18 \mathrm{~S}$ CT value of $<23$ were assumed to contain RNA of sufficient quality for analysis of VEGF-B expression. To determine the relative RNA levels within the samples, standard curves for the PCR reaction were prepared by using the cDNA from one sample and making 2-fold serial dilutions covering the range equivalent to 39.2$1.6 \mathrm{ng}$ of RNA. The relative standard curve method was used to determine the fold change in VEGF-B expression in treated and untreated cells.

Statistical analysis. Experiments were performed in triplicate with the exception of microarray experiments which were performed in sextuplicate. In bromodeoxyuridine experiments the coefficient of variation over the range measured was $11 \%$ in experiments using transfected cells and $7 \%$ in experiments using untransfected cells. Data were analysed using the Student's t-test and $\mathrm{p}<0.05$ were considered significant.

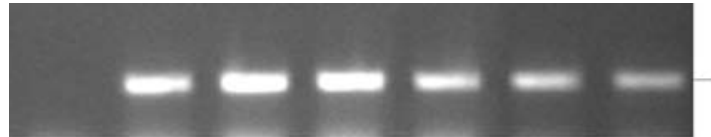

$\mathrm{A}$

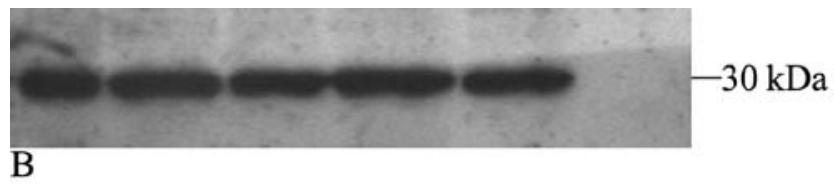

Figure 1. (A) PCR confirmation of dermcidin transfection in $\mathrm{HuH7}$ cells The expected PCR product of the full length native cDNA is $387 \mathrm{bp}$. Lane 1, untransfected HuH7 cell cDNA, early passage. Lane 2, untransfected $\mathrm{HuH7}$ cDNA, prolonged passage. Lane 3, empty pcDNA3.1+transfected $\mathrm{HuH7}$ cDNA. Lane 4, pcDNA3.1+dermcidin transfected HuH7 cDNA. Lane 5, pcDNA3.1+ProP STOP transfected HuH7 cDNA. Lane 6, pcDNA3.1+Y-P30 STOP transfected HuH7 cDNA. Lane 7, pcDNA3.1+H35N transfected HuH7 cDNA. (B) Anti-neomycin phsophtransferase Western blotting to assess HuH7 cell transfection. The molecular mass of neomycin phosphotransferase is $30 \mathrm{kDa}$. Lane 1, empty vector transfected $\mathrm{HuH} 7$ cell lysate. Lane 2, pcDNA3.1+dermcidin transfected $\mathrm{HuH7}$ cell lysate. Lane 3, pcDNA3.1+ProP STOP transfected HuH7 cell lysate. Lane 4, pcDNA3.1+Y-P30 STOP transfected HuH7 cell lysate. Lane 5, pcDNA3.1+H35N transfected HuH7 cell lysate. Lane 6, untransfected $\mathrm{HuH7}$ cell lysate.

\section{Results}

Creation of dermcidin mutants. Site-directed mutagenesis was used to alter the codons within the native DCD cDNA in the pcDNA3.1+mammalian expression vector. The potentially-glycosylated asparagine residues of the calcineurin-like phosphatase domain were removed by substituting glutamine for asparagine in the N32Q, N44Q and N32Q N44Q mutants. A further mutation to eliminate the most highly conserved residue of this domain was also designed, which converted the histidine residue at position 35 to asparagine. This mutation has been demonstrated previously to prevent phosphatase activity in calcineurin (29). Additionally, two truncation mutants were generated by inserting STOP codons immediately $5^{\prime}$ to the propeptide sequence (which is $5^{\prime}$ to the DCD-1 sequence) in the ProP STOP vector and immediately 5 ' to the Y-P30 sequence in the Y-P30 STOP vector. Due to a high $\mathrm{A}$ and $\mathrm{T}$ content it was not possible to design primers to introduce a STOP codon immediately prior to the DCD-1 sequence which were compatible with the Quikchange mutagenesis system's annealing temperatures. All mutated plasmid sequences were confirmed by direct sequencing.

PCR of cDNA from all transfected cells confirmed expression (Fig. 1A). A low level of background DCD expression developed following prolonged culture (same number of passages as transfected cells) of untransfected $\mathrm{HuH7}$ cells as previously described (8). The short nature of the translated sequences and their predicted low antigenicity rendered the generation of antibodies to each mutant peptide unfeasible. Anti-neomycin phosphotransferase confirmed that the vectors were active only in transfected cells (Fig. 1B). All effects of transfection were subsequently controlled for. Assessment of protein expression in $\mathrm{HuH7}$ cells transfected with the N32Q, N44Q, N32QN44Q vectors has previously been performed in the same manner (8). 


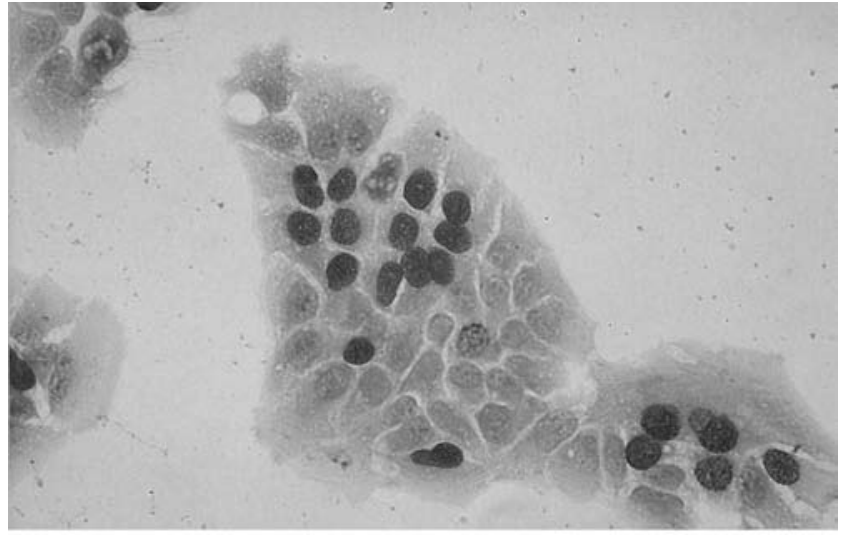

A

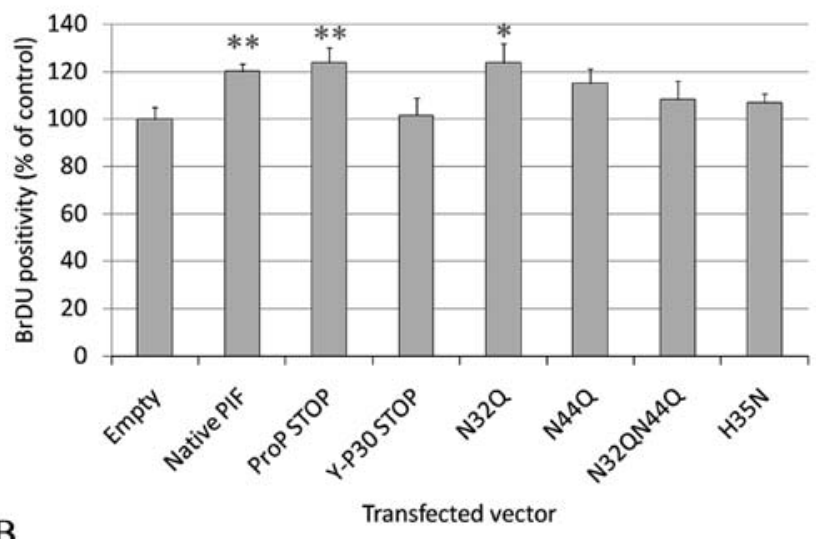

Figure 2. Transfected $\mathrm{HuH} 7$ cell proliferation assay. (A) Representative immunocytochemical appearance. (B) Effect of different pcDNA3.1+vector inserts on the proportion of transfected $\mathrm{HuH7}$ cells staining for BrDU. Cells $\left(1 \times 10^{5}\right)$ per well were seeded in 8-well slide chambers and cultured for $24 \mathrm{~h}$. Staining was then performed with a rat anti-BrDU primary antibody and goat anti-rat peroxidase-linked secondary antibody. Slides were stained with a liquid DAB+substrate chromogen system and haematoxylin counterstaining. Positive and negative nuclei were counted using a graticule. $\mathrm{HuH} 7$ cells transfected with the native DCD cDNA, the ProP STOP mutant and the N32Q mutant showed a significant increase in cell proliferation in comparison with empty vector-transfected cells. This increase was effectively abrogated by the Y-P30 STOP and H35N STOP mutations. The N44Q and N32QN44Q mutations had lesser effects. ${ }^{*} \mathrm{p}<0.05 .{ }^{* *} \mathrm{p}<0.02$ (t-test).

Assessment of cell proliferation in transfected $\mathrm{HuH7}$ cells. BrDU immunocytochemistry of DCD-transfected $\mathrm{HuH7}$ cells resulted in clearly distinguishable positive and negative nuclear staining (Fig. 2A). The proportion of positively staining sham-transfected cells was $29 \%$. Stable transfection of the native DCD-containing vector pcDNA3.1+dermcidin resulted in a $20 \%$ increase in cells positive for $\mathrm{BrDU}$ in comparison with transfection with the empty vector (Fig. 2B) (Student's t-test, $\mathrm{p}<0.02)$. Transfection of the ProP STOP and N32Q mutants resulted in similar significant increases in cell proliferation of $23 \%$ (Student's t-test, $\mathrm{p}<0.02$ and $\mathrm{p}<0.05$ respectively). A lower, non-significant increase in proliferation of $15 \%$ was seen in the N44Q mutant. The Y-P30 STOP, N32QN44Q and $\mathrm{H} 35 \mathrm{~N}$ mutants resulted in non-significant increases in proliferation of 2,8 and $7 \%$ respectively (Fig. 2B).

Induction of cell proliferation by a synthetic PIF-CP peptide. $\mathrm{HuH} 7$ cells treated with the synthetic PIF-CP peptide showed

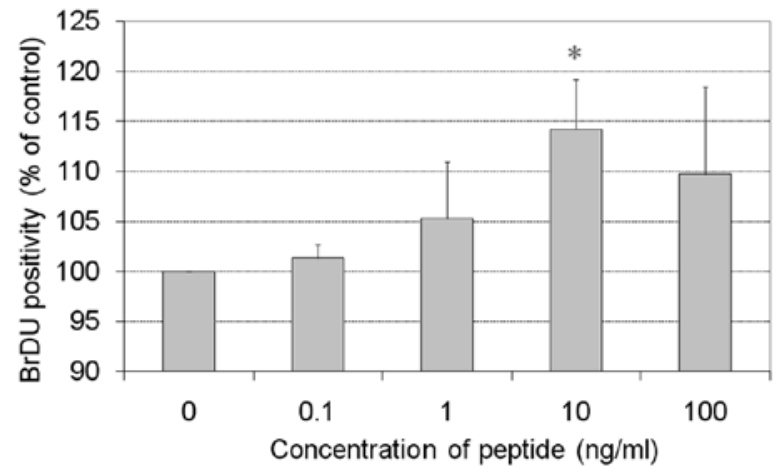

Figure 3. Effect of treatment of $\mathrm{HuH7}$ cells with a synthetic peptide corresponding to the PIF-core peptide. Cells were seeded at 10,000 cells per well in 8-well chambered slides and cultured overnight under standard conditions. They were then cultured for $24 \mathrm{~h}$ in standard medium containing a range of concentrations of synthetic PIF-core peptide. A dose-dependent increase in cells staining positive for BrDU was observed which peaked at a peptide concentration of $10 \mathrm{ng} / \mathrm{ml}$. ${ }^{*} \mathrm{p}<0.05$ (t-test).

no identifiable changes in cell morphology. Cell counts for BrDU positivity revealed that the synthetic peptide increased cell proliferation (Fig. 3). The response had a bell-shaped dose-response curve and produced a maximum increase of $14 \%$ at a peptide concentration of $10 \mathrm{ng} / \mathrm{ml}$ (Student's t-test, $\mathrm{p}<0.05)$.

Effect of PIF-CP peptide treatment on HuH7 gene expression. For microarray analysis, $\mathrm{HuH7}$ cells treated with the synthetic PIF peptide were compared with untreated cells. There were 111 genes with a fold change $\geq 1.25$ and empirical Bayes test $\mathrm{p} \leq 0.05$. For brevity, 51 genes with a fold change $\geq 1.3$ and empirical Bayes test $\mathrm{p} \leq 0.05$ are presented in Table I. To further investigate the differential expression observed we sought to analyse the networks, functions and pathways in which these genes played a role. Pathways analysis of the differentially expressed genes using Ingenuity Pathways Analysis (Ingenuity Systems) revealed 4 networks of high connectivity containing a high number of PIF peptide-regulated genes. Network 3 (network score of 23 and 14/35 focus molecules) centred on FOS, LIF, VEGF, ERBB2 and HRAS, of which VEGFB was directly regulated by the PIF-CP peptide. Upregulation of VEGFB expression was confirmed by real-time PCR which demonstrated a mean increase in expression similar to that of microarray experiments of 1.89-fold. Network 1 (network score of 25 and 15/35 focus molecules) centred on TNF, TGF $\beta 1$ and IL-4, although none of these genes were directly regulated by the PIF-CP peptide. Network 2 (network score of 23 and 14/35 focus molecules) centred on TP5 3, THRB and MYOD1, none of which were directly regulated by the PIF-CP peptide. Network 4 (network score of 18 and 12/35 focus molecules) centred on HGF and MYC, neither of which were directly regulated by the PIF peptide.

Analysis of the functional groupings of the most variable 1500 genes revealed the most significant changes in expression of genes involved in cardiovascular system development and function, cell morphology, skeletal and muscular system development and function, cancer, cell death and the cell cycle (Fig. 4A). 


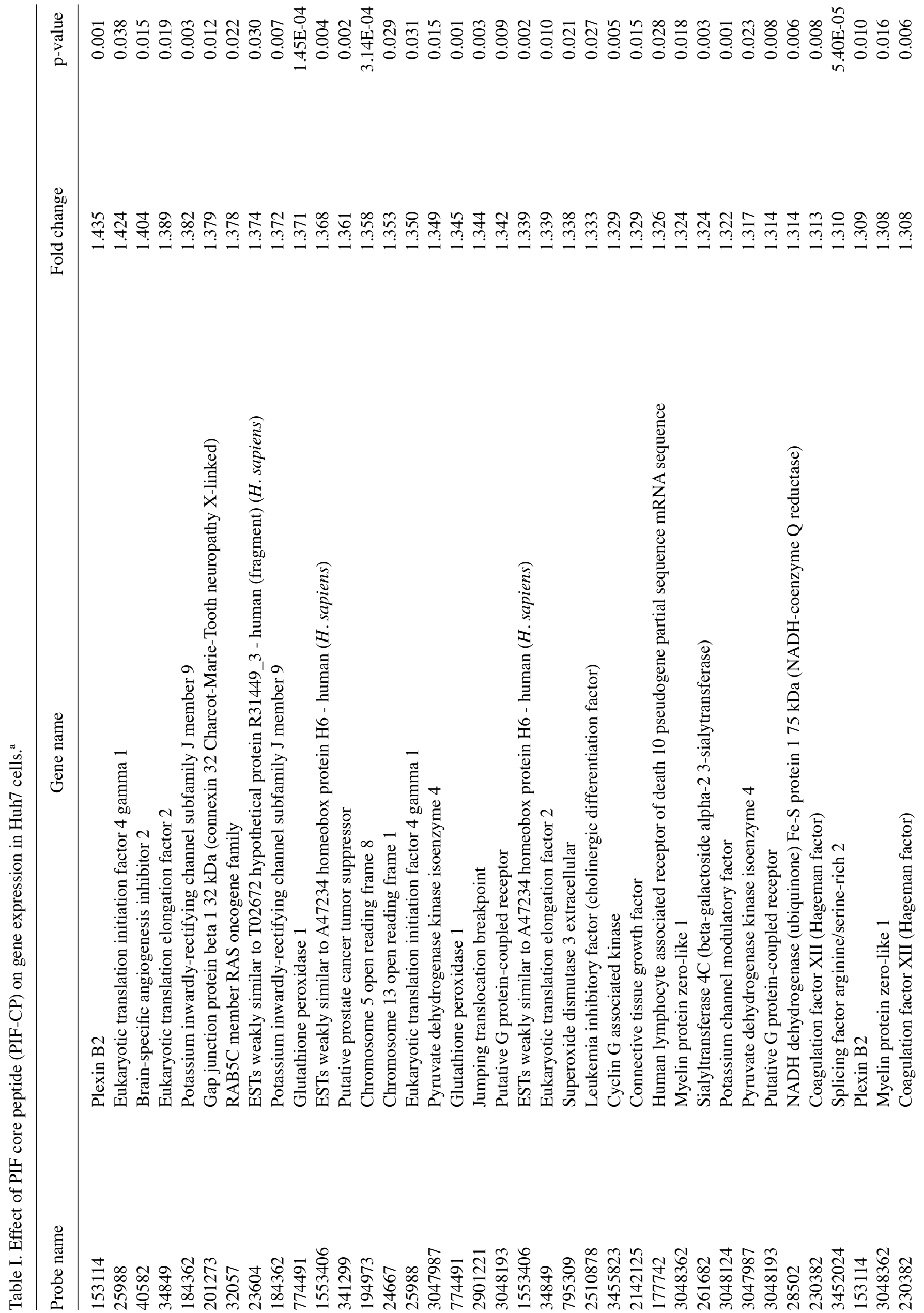



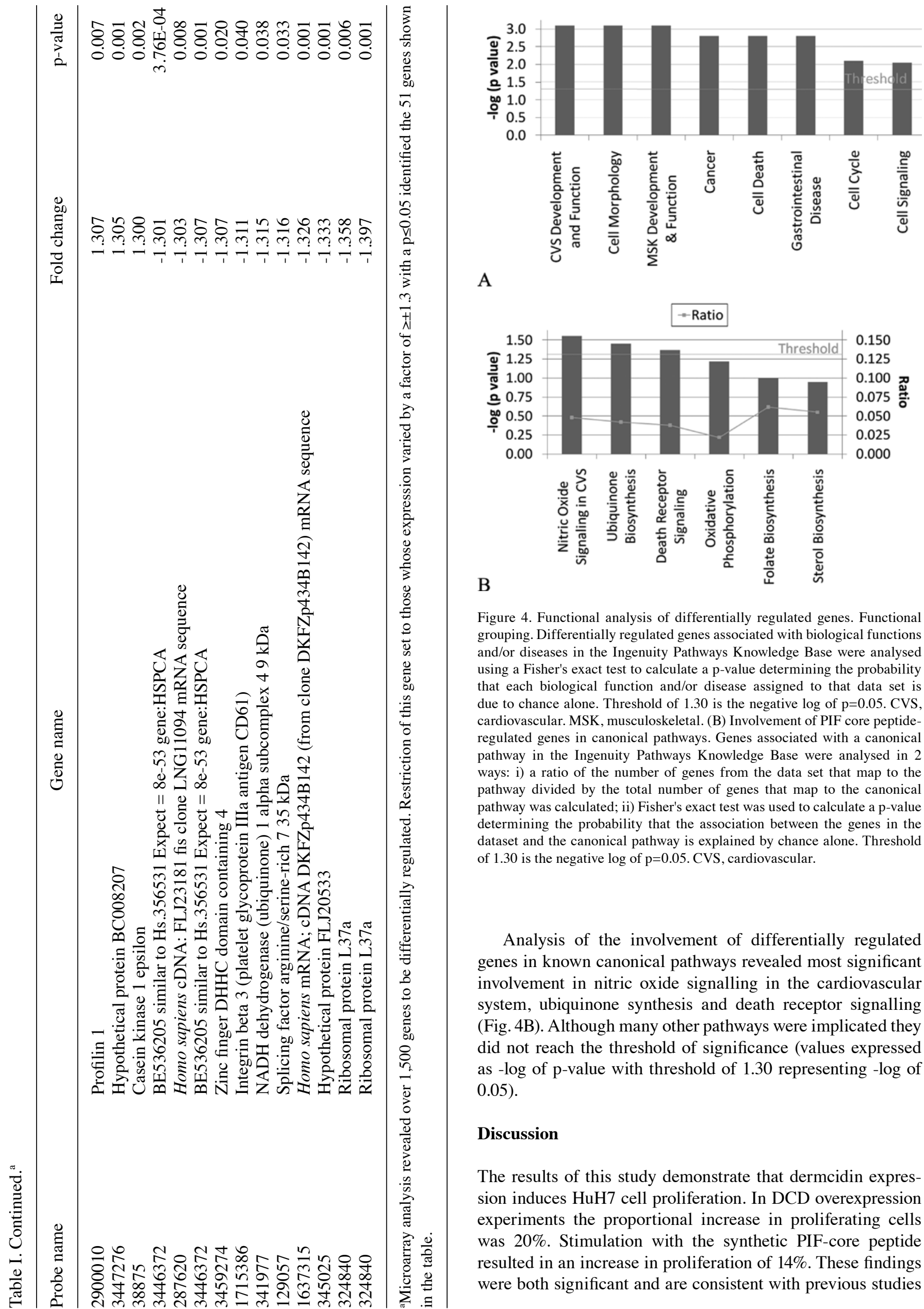

A

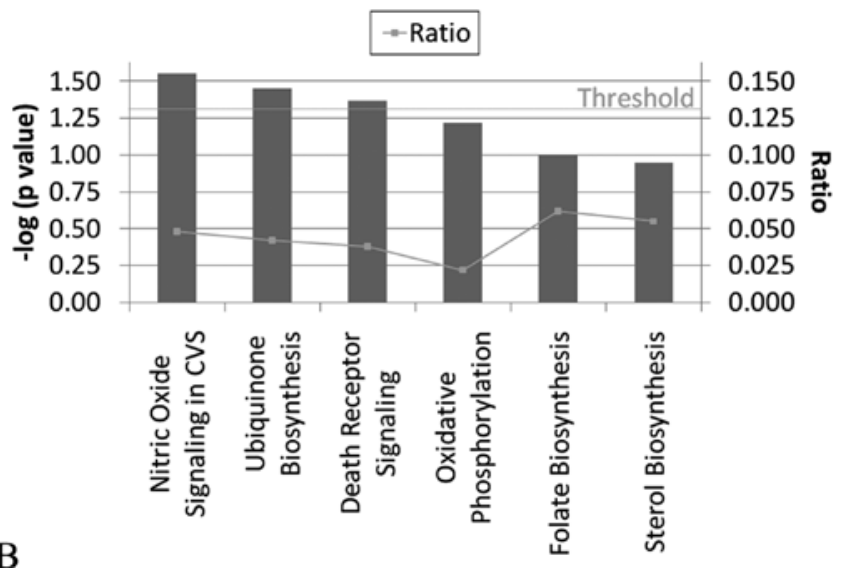

Figure 4. Functional analysis of differentially regulated genes. Functional grouping. Differentially regulated genes associated with biological functions and/or diseases in the Ingenuity Pathways Knowledge Base were analysed using a Fisher's exact test to calculate a p-value determining the probability that each biological function and/or disease assigned to that data set is due to chance alone. Threshold of 1.30 is the negative $\log$ of $p=0.05$. CVS, cardiovascular. MSK, musculoskeletal. (B) Involvement of PIF core peptideregulated genes in canonical pathways. Genes associated with a canonical pathway in the Ingenuity Pathways Knowledge Base were analysed in 2 ways: i) a ratio of the number of genes from the data set that map to the pathway divided by the total number of genes that map to the canonical pathway was calculated; ii) Fisher's exact test was used to calculate a p-value determining the probability that the association between the genes in the dataset and the canonical pathway is explained by chance alone. Threshold of 1.30 is the negative $\log$ of $p=0.05$. CVS, cardiovascular.

Analysis of the involvement of differentially regulated genes in known canonical pathways revealed most significant involvement in nitric oxide signalling in the cardiovascular system, ubiquinone synthesis and death receptor signalling (Fig. 4B). Although many other pathways were implicated they did not reach the threshold of significance (values expressed as $-\log$ of $\mathrm{p}$-value with threshold of 1.30 representing -log of 0.05).

\section{Discussion}

The results of this study demonstrate that dermcidin expression induces HuH7 cell proliferation. In DCD overexpression experiments the proportional increase in proliferating cells was $20 \%$. Stimulation with the synthetic PIF-core peptide resulted in an increase in proliferation of $14 \%$. These findings were both significant and are consistent with previous studies 
on the proliferative effects of DSEP/dermcidin expression (1-3). The increased proportion of cells entering S-phase demonstrated by BrDU staining suggests cell cycling rather than decreased cell death secondary to the pro-survival effects of DCD expression (8).

When translation of the sequence 3 ' to Y-P30 including the propeptide and DCD-1 coding areas (ProP STOP mutant) was prevented there was little effect on dermcidin-induced proliferation suggesting these peptides are not crucial for this effect. In contrast, when translation of the Y-P30 sequence was prevented the proliferative effect of overexpression was abrogated. This suggests that the Y-P30/PIF-core peptide is responsible for the proliferative effects of dermcidin. Experiments using the synthetic PIF-core peptide support this conclusion in that proliferation of a similar magnitude was observed. The bell-shaped dose-response curve following Huh7 treatment with synthetic PIF-CP is characteristic of biological responses to several cytokines and growth factors including IFN- $\gamma$, IL-6, IL-8 and TNF- $\alpha$ (30-33). It has also been suggested that bell-shaped dose-response curves may result from the action of an agonist on two separate receptors (34). It is therefore intriguing to hypothesise that $\mathrm{HuH} 7$ cells may express both the high- and low-affinity receptors previously reported $(2,35)$, and that these receptors may have differential effects on proliferation.

The finding that dermcidin-induced cell proliferation is prevented by the N32QN44Q and $\mathrm{H} 35 \mathrm{~N}$ mutations further supports the role of the PIF-CP in the induction of proliferation, as both of these mutations lie within the PIF-CP amino acid sequence. Furthermore, these mutations lie within the calcineurin phosphatase-like domain (5). An effect of calcineurin signalling on cell proliferation has previously been demonstrated in pancreatic cancer cells and interestingly this effect was mediated by myc, which we found to be a key mediator in network 4 (36). Histidine is the most highly conserved amino acid across the calcineurin-like family of phosphatases (37) and its removal has been demonstrated to cause a significant decrease in enzyme activity $(29,38)$. It is therefore feasible that the replacement of histidine with asparagine in the $\mathrm{H} 35 \mathrm{~N}$ mutant reduces Y-P30 phosphatase activity. The reason for the lack of proliferative effect of the N32QN44Q mutant is less clear. This mutation does not appear to affect N-glycosylation in $\mathrm{HuH} 7$ cells (8) and the single mutations N32Q and N44Q did not affect proliferation. In the calcineurin phosphatase domain, the role of asparagine residues has not been investigated, although they are a conserved part of the active phosphatase site (37). Mutation of both asparagines may therefore disrupt the phosphatase site but mutation of either alone appears insufficient to do so. One way to test this hypothesis would be to extend the studies of para-nitrophenyl phosphate cleavage by Y-P30 performed by Cunningham et al (5). In particular, synthesis of peptides containing the $\mathrm{H} 35 \mathrm{~N}$ and $\mathrm{N} 32 \mathrm{QN} 44 \mathrm{Q}$ mutations and comparison of their proliferative effects with those of the native peptide would help elucidate the role of these amino acids in DCD/PIF-CP induced proliferation.

Microarray analysis showed relatively small fold-changes in gene expression mediated by the PIF-core peptide. This may, in part, reflect the experimental and analytical methods used. The technique of LOWESS normalisation used to correct for dye bias assumes that this bias is dependent on spot intensity with the subsequent effect of smoothing all signals. Similarly, the use of reciprocal Cy3/Cy5 labelling for sample and control specimens would be expected to lessen overall fold-changes. Nevertheless, the fact that synthetic PIF-CP treatment had a small effect on the magnitude of gene expression changes suggests that its effect on proliferation is more likely to be mediated through a change in the pattern of expression rather than the control of a single 'switch' gene. Ingenuity Pathways Analysis was performed to examine networks of interacting genes differentially expressed after PIF treatment. As the microarray platform used in this study did not provide full coverage of the human genome differential expression data were not available for many of the potential interacting partners in networks or canonical pathways. Despite this however, Ingenuity Pathways Analysis revealed several networks of high connectivity which may mediate the proliferative effect of the PIF-CP. In network 1, peptide treatment increased CCNB1 (cyclin B1) expression. As part of the cyclin B1-CDK1 complex this would be expected to promote progress from $\mathrm{G} 2$ to $\mathrm{M}$, contributing to the highly complex activation of cyclin B1 (39). In network 2, the IGFBP2 growth factor binding protein, previously demonstrated to promote Akt-driven transformation (40), was upregulated. However, in $\mathrm{HuH} 7$ cells IGFBP2 has previously been demonstrated to be secreted on growth inhibition by histone deacetylase treatment (41). It is not clear if IGFBP2 expression reflects a pro-proliferative 'escape' effect or an anti-proliferative effect in this model. In network 3, VEGFB was upregulated. This response was validated using real-time PCR. VEGF is known to be produced by $\mathrm{HuH} 7$ cells and has pro-proliferative in addition to its well-characterised angiogenic effects (42-45). Network 3 was unusual in converging on a single nuclear target, FOS. FOS has been well defined as a pro-proliferative oncogene, but in $\mathrm{HuH} 7$ cells appears to mediate myc-instigated apoptosis $(46,47)$. Myc is known to function as a pivot, determining whether cells undergo apoptosis or growth, and it is therefore possible that its status could influence the effect of network 3. Interestingly, myc and fos are central in network 4, and although not directly regulated by PIF-CP, myc interacts with several directly regulated genes. Determining or creating changes in the status of fos and myc may cast light on the influence of dermcidin-regulated genes on proliferation.

Functional analysis of differentially regulated genes suggested their involvement in cardiovascular system development and function, cell morphology, skeletal and muscular development and function, cancer, cell death, gastrointestinal disease and cell cycling. These functions and in particular cell cycling are all consistent with the proliferative effect observed in $\mathrm{HuH} 7$ cells. Similarly, they support the previously described functions of dermcidin as an oncogene (2), survival peptide $(5,8)$ and cachectic factor $(6)$. These functions have also previously been ascribed to the Y-P30/PIF core peptide. No anti-microbial function was found and this is consistent with the antibiotic action of dermcidin being mediated by the DCD-1 peptide rather than the PIF-CP (7). The regulation of genes involved in cardiovascular system development and function, cell morphology and gastrointestinal disease suggests dermcidin may have previously unrecognised functions in these areas. 
Pathways analysis demonstrated statistically significant involvement of PIF-CP-regulated genes in 3 pathways: nitric oxide signalling in the cardiovascular system, ubiquinone biosynthesis and death receptor signalling. Dermcidin expression is known to protect cells from oxidative stress $(5,8,48)$ and it is feasible that this effect involves part of the nitric oxide signalling pathway. However, a functional role in the cardiovascular system has not been described. Dermcidin has similarly not previously been demonstrated to play a role in ubiquinone biosynthesis. Ubiquinone's roles in the respiratory chain (49) and in the prevention of ceramide-induced apoptosis $(50,51)$ suggest that it may also be a mechanism involved in the pro-survival effect of dermcidin $(5,8)$. Ubiquinone is involved in the intrinsic pathway of apoptosis. The possibility that dermcidin also influences the extrinsic pathway is raised by its regulation of genes with functions in death receptor signalling. A combination of genes involved in both pathways may explain its pro-survival effect.

The finding that dermcidin induces tumour cell proliferation confirms its oncogenic potential. Autocrine secretion of dermcidin would be expected to contribute to the autonomous growth of tumour cells. DCD has recently been shown to have a differential level of expression across different tumour types, with bilio-pancreatic tumours having the greatest levels of expression (48). Overexpression has been suggested to occur through the amplification of the dermcidin gene locus in breast cancer (2). Alternatively, as with other oncogene pathways involving secreted products, abnormalities in the receptor system or signalling pathways could contribute to tumour cell expansion (52). Of the signalling pathways known to be stimulated by glycosylated PIF, there is some evidence that the proteasome pathway may be involved in the induction of cell proliferation. In pancreatic cancer, inhibition of the $26 \mathrm{~S}$ proteasome has been found to inhibit proliferation, potentially via prevention of $\mathrm{p} 21^{\mathrm{WAF}-1}$ degradation (53). It is feasible that a similar effect in $\mathrm{HuH} 7$ cells could contribute to the pro-proliferative effects we have observed $(54,55)$.

We have demonstrated that dermcidin has proliferative effects in $\mathrm{HuH} 7$ cells which are mediated via the Y-P30/ PIF-CP peptides and probably the calcineurin phosphatase-like domain. Further studies correlating inhibition of dermcidin-regulated genes with its pro-proliferative effects will aid in determining the exact mechanisms responsible. We have also identified several functions and pathways not previously known to be regulated by dermcidin. Their study may reveal important new biological roles.

\section{Acknowledgements}

We are grateful to Peter Ghazal, Division of Pathway Medicine for his support of the microarray experiments. This work was supported by funding from the Royal College of Surgeons of Edinburgh and the Melville Trust for the Care and Cure of Cancer.

\section{References}

1. Cunningham TJ, Jing H, Akerblom I, Morgan R, Fisher TS and Neveu M: Identification of the human cDNA for new survival/ evasion peptide (DSEP): studies in vitro and in vivo of overexpression by neural cells. Exp Neurol 177: 32-39, 2002.
2. Porter D, Weremowicz S, Chin K, Seth P, Keshaviah A, LahtiDomenici J, Bae YK, Monitto CL, Merlos-Suarez A, Chan J, Hulette CM, Richardson A, Morton CC, Marks J, Duyao M, Hruban R, Gabrielson E, Gelman R and Polyak K: A neural survival factor is a candidate oncogene in breast cancer. Proc Natl Acad Sci USA 100: 10931-10936, 2003.

3. Stewart GD, Lowrie AG, Riddick AC, Fearon KC, Habib FK and Ross JA: Dermcidin expression confers a survival advantage in prostate cancer cells subjected to oxidative stress or hypoxia. Prostate 67: 1308-1317, 2007.

4. Stewart GD, Skipworth RJ, Pennington CJ, Lowrie AG, Deans DA, Edwards DR, Habib FK, Riddick AC, Fearon KC and Ross JA: Variation in dermcidin expression in a range of primary human tumours and in hypoxic/oxidatively stressed human cell lines. Br J Cancer 99: 126-132, 2008.

5. Cunningham TJ, Hodge L, Speicher D, Reim D, Tyler-Polsz C, Levitt P, Eagleson K, Kennedy S and Wang Y: Identification of a survival-promoting peptide in medium conditioned by oxidatively stressed cell lines of nervous system origin. J Neurosci 18: 7047-7060, 1998

6. Todorov P, Cariuk P, McDevitt T, Coles B, Fearon K and Tisdale M: Characterization of a cancer cachectic factor. Nature 379: 739-742, 1996.

7. Schittek B, Hipfel R, Sauer B, Bauer J, Kalbacher H, Stevanovic S, Schirle M, Schroeder K, Blin N, Meier F, Rassner G and Garbe C: Dermcidin: a novel human antibiotic peptide secreted by sweat glands. Nat Immunol 2: 1133-7113, 2001.

8. Lowrie AG, Wigmore SJ, Wright DJ, Waddell ID and Ross JA: Dermcidin expression in hepatic cells improves survival without $\mathrm{N}$-glycosylation, but requires asparagine residues. Br J Cancer 94: 1663-1671, 2006.

9. Bommireddy R, Ormsby I, Yin M, Boivin GP, Babcock GF and Doetschman T: TGF beta 1 inhibits $\mathrm{Ca}^{2+}$-calcineurinmediated activation in thymocytes. J Immunol 170: 3645-3652, 2003.

10. Baksh S, De Caprio JA and Burakoff SJ: Calcineurin regulation of the mammalian G0/G1 checkpoint element, cyclin dependent kinase 4. Oncogene 19: 2820-2827, 2000.

11. De Chassey B, Mikaelian I, Mathieu AL, Bickle M, Olivier D, Nègre D, Cosset FL, Rudkin BB and Colas P: An antiproliferative genetic screening identifies a peptide aptamer that targets calcineurin and up-regulates its activity. Mol Cell Proteomics 6: 451-459, 2007.

12. Cunningham TJ, Jing $H$, Wang $Y$ and Hodge L: Calreticulin binding and other biological activities of survival peptide Y-P30 including effects of systemic treatment of rats. Exp Neurol 163: 457-468, 2000.

13. Gold LI, Rahman M, Blechman KM, Greives MR, Churgin S, Michaels J, Callaghan MJ, Cardwell NL, Pollins AC, Michalak M, Siebert JW, Levine JP, Gurtner GC, Nanney LB, Galiano RD and Cadacio CL: Overview of the role for calreticulin in the enhancement of wound healing through multiple biological effects. J Investig Dermatol Symp Proc 11: 57-65, 2006 .

14. Smith HJ and Tisdale MJ: Signal transduction pathways involved in proteolysis-inducing factor induced proteasome expression in murine myotubes. Br J Cancer 89: 1783-1788, 2003.

15. Watchorn TM, Waddell I, Dowidar N and Ross JA: Proteolysisinducing factor regulates hepatic gene expression via the transcription factors NF-(kappa)B and STAT3. FASEB J 15: 562-564, 2001.

16. Watchorn TM, Waddell I and Ross JA: Proteolysis-inducing factor differentially influences transcriptional regulation in endothelial subtypes. Am J Physiol Endocrinol Metab 282: 763-769, 2002.

17. Watchorn TM, Dowidar N, Dejong CH, Waddell ID, Garden OJ and Ross JA: The cachectic mediator proteolysis inducing factor activates NF-kappaB and STAT3 in human Kupffer cells and monocytes. Int J Oncol 27: 1105-1111, 2005.

18. Kirillova I, Chaisson M and Fausto N: Tumor necrosis factor induces DNA replication in hepatic cells through nuclear factor kappaB activation. Cell Growth Differ 10: 819-828, 1999.

19. Kountouras J, Boura P and Lygidakis NJ: Liver regeneration after hepatectomy. Hepatogastroenterology 48: 556-562, 2001.

20. Liptay S, Weber CK, Ludwig L, Wagner M, Adler G and Schmid RM: Mitogenic and antiapoptotic role of constitutive NF-kappaB/Rel activity in pancreatic cancer. Int J Cancer 105: 735-746, 2003. 
21. Scholz A, Heinze S, Detjen KM, Peters M, Welzel M, Hauff P, Schirner M, Wiedenmann B and Rosewicz S: Activated signal transducer and activator of transcription 3 (STAT3) supports the malignant phenotype of human pancreatic cancer. Gastroenterology 125: 891-905, 2003.

22. Li L, Aggarwal BB, Shishodia S, Abbruzzese J and Kurzrock R Nuclear factor-kappaB and IkappaB kinase are constitutively active in human pancreatic cells, and their down-regulation by curcumin (diferuloylmethane) is associated with the suppression of proliferation and the induction of apoptosis. Cancer 101: 2351-2362, 2004.

23. Yao P, Zhan Y, Xu W, Li C, Yue P, Xu C, Hu D, Qu C and Yang $\mathrm{X}$ : Hepatocyte growth factor-induced proliferation of hepatic stem-like cells depends on activation of NF-kappaB. J Hepatol 40: 391-398, 2004.

24. Ohira H, Miyata M, Kuroda M, Takagi T, Tojo J, Ochiai H, Kokubun M, Nishimaki T, Kasukawa $R$ and Obara $K$ : Interleukin- 6 induces proliferation of rat hepatocytes in vivo. $\mathrm{J}$ Hepatol 25: 941-947, 1996.

25. Li A, Varney ML, Valasek J, Godfrey M, Dave BJ and Singh RK: Autocrine role of interleukin-8 in induction of endothelial cell proliferation, survival, migration and MMP-2 production and angiogenesis. Angiogenesis 8: 63-71, 2005.

26. De Luca LM: Retinoids and their receptors in differentiation, embryogenesis, and neoplasia. FASEB J 5: 2924-2933, 1991.

27. Dedhar S, Rennie PS, Shago M, Hagesteijn CY, Yang $H$, Filmus J, Hawley RG, Bruchovsky N, Cheng H and Matusik RJ: Inhibition of nuclear hormone receptor activity by calreticulin. Nature 367: 480-483, 1994

28. Smyth GK: Linear models and empirical Bayes methods for assessing differential expression in microarray experiments. Statist Appl Genet Mol Biol 3: 3, 2004.

29. Mertz P, Yu L, Sikkink R and Rusnak F: Kinetic and spectroscopic analyses of mutants of a conserved histidine in the metallophosphatases calcineurin and lambda protein phosphatase. J Biol Chem 272: 21296-21302, 1997.

30. Talmadge JE, Tribble HR, Pennington RW, Phillips $H$ and Wiltrout RH: Immunomodulatory and immunotherapeutic properties of recombinant gamma-interferon and recombinant tumor necrosis factor in mice. Cancer Res 47: 2563-2570, 1987.

31. Utsunomiya I, Ito M, Watanabe K, Tsurufuji S, Matsushima K and Oh S: Infiltration of neutrophils by intrapleural injection of tumour necrosis factor, interleukin-1, and interleukin-8 in rats, and its modification by actinomycin $\mathrm{D}$. Br J Pharmacol 117: 611-614, 1996.

32. Ben-Baruch A, Bengali K, Tani K, Xu L, Oppenheim JJ and Wang JM: IL-8 and NAP-2 differ in their capacities to bind and chemoattract 293 cells transfected with either IL-8 receptor type A or type B. Cytokine 9: 37-45, 1997.

33. Tsigos C, Papanicolaou DA, Kyrou I, Raptis SA and Chrousos GP: Dose-dependent effects of recombinant human interleukin-6 on the pituitary-testicular axis. J Interferon Cytokine Res 19: 1271-1276, 1999.

34. Ashby B: Novel mechanism of heterologous desensitization of adenylate cyclase: prostaglandins bind with different affinities to both stimulatory and inhibitory receptors on platelets. Mol Pharmacol 38: 46-53, 1990.

35. Todorov PT, Wyke SM and Tisdale MJ: Identification and characterization of a membrane receptor for proteolysis-inducing factor on skeletal muscle. Cancer Res 67: 11419-11427, 2007.

36. Buchholz M, Schatz A, Wagner M, Michl P, Linhart T, Adler G, Gress TM and Ellenrieder V: Overexpression of c-myc in pancreatic cancer caused by ectopic activation of NFATc1 and the $\mathrm{Ca}^{2+} /$ calcineurin signaling pathway. EMBO J 25: 3714-3724, 2006.

37. Rusnak F and Mertz P: Calcineurin: form and function. Physiol Rev 80: 1483-1521, 2000.

38. Zhuo S, Clemens JC, Stone RL and Dixon JE: Mutational analysis of a Ser/Thr phosphatase. Identification of residues important in phosphoesterase substrate binding and catalysis. J Biol Chem 269: 26234-26238, 1994.
39. Porter LA and Donoghue DJ: Cyclin B1 and CDK1: nuclear localization and upstream regulators. Prog Cell Cycle Res 5: 335-347, 2003.

40. Mehrian-Shai R, Chen CD, Shi T, Horvath S, Nelson SF, Reichardt JK and Sawyers CL: Insulin growth factor-binding protein 2 is a candidate biomarker for PTEN status and PI3K/ Akt pathway activation in glioblastoma and prostate cancer. Proc Natl Acad Sci USA 104: 5563-5568, 2007.

41. Chiba T, Yokosuka O, Fukai K, Kojima H, Tada M, Arai M, Imazeki $\mathrm{F}$ and Saisho $\mathrm{H}$ : Cell growth inhibition and gene expression induced by the histone deacetylase inhibitor, trichostatin $\mathrm{A}$, on human hepatoma cells. Oncology 66: 481-491, 2004.

42. Grunfeld C, Zhao C, Fuller J, Pollack A, Moser A, Friedman J and Feingold KR: Endotoxin and cytokines induce expression of leptin, the ob gene product, in hamsters. J Clin Invest 97: 2152-2157, 1996.

43. Tsukamoto A, Kaneko Y, Yoshida T, Ichinose M and Kimura S: Regulation of angiogenesis in human hepatomas: possible involvement of p53-inducible inhibitor of vascular endothelial cell proliferation. Cancer Lett 141: 79-84, 1999.

44. Gu S, Liu CJ, Qiao T, Sun XM, Chen LL and Zhang L: Inhibitory effect of antisense vascular endothelial growth factor 165 eukaryotic expression vector on proliferation of hepatocellular carcinoma cells. World J Gastroenterol 10: 535-539, 2004.

45. Hao JH, Yu M, Li HK, Shi YR, Li Q and Hao XS: Inhibitory effect of antisense vascular endothelial growth factor RNA on the profile of hepatocellular carcinoma cell line in vitro and in vivo. World J Gastroenterol 12: 1140-1143, 2006.

46. Van Dam DH and Castellazzi M: Distinct roles of Jun: Fos and Jun: ATF dimers in oncogenesis. Oncogene 20: 2453-2464, 2001.

47. Kalra $\mathrm{N}$ and Kumar V: c-Fos is a mediator of the c-myc-induced apoptotic signaling in serum-deprived hepatoma cells via the p38 mitogen-activated protein kinase pathway. J Biol Chem 279: 25313-25319, 2004.

48. Stewart GD, Skipworth RJ, Ross JA, Fearon KC and Baracos VE: The dermcidin gene in cancer: role in cachexia, carcinogenesis and tumour cell survival. Curr Opin Clin Nutr Metab Care 11: 208-213, 2008

49. Ernster L and Dallner G: Biochemical, physiological and medical aspects of ubiquinone function. Biochim Biophys Acta 1271: 195-204, 1995.

50. Barroso MP, Gomez-Diaz C, Villalba JM, Buron MI, LopezLluch G and Navas P: Plasma membrane ubiquinone controls ceramide production and prevents cell death induced by serum withdrawal. J Bioenerg Biomembr 29: 259-267, 1997.

51. Villalba JM and Navas P: Plasma membrane redox system in the control of stress-induced apoptosis. Antioxid Redox Signal 2: 213-230, 2000

52. Downward J, Yarden Y, Mayes E, Scrace G, Totty N, Stockwell P, Ullrich A, Schlessinger J and Waterfield MD: Close similarity of epidermal growth factor receptor and v-erb-B oncogene protein sequences. Nature 307: 521-527, 1984.

53. Shah SA, Potter MW, McDade TP, Ricciardi R, Perugini RA, Elliott PJ, Adams J and Callery MP: 26S proteasome inhibition induces apoptosis and limits growth of human pancreatic cancer. J Cell Biochem 82: 110-122, 2001.

54. Lorite MJ, Smith HJ, Arnold JA, Morris A, Thompson MG and Tisdale MJ: Activation of ATP-ubiquitin-dependent proteolysis in skeletal muscle in vivo and murine myoblasts in vitro by a proteolysis-inducing factor (PIF). Br J Cancer 85: 297-302, 2001.

55. Whitehouse AS and Tisdale MJ: Increased expression of the ubiquitin-proteasome pathway in murine myotubes by proteolysis-inducing factor (PIF) is associated with activation of the transcription factor NF-kappaB. Br J Cancer 89: 1116-1122, 2003. 